\title{
SIMPLIFIED ANALYSIS OF SHEAR-LAG IN FRAMED-TUBE STRUCTURES WITH MULTIPLE INTERNAL TUBES
}

\author{
Kang-Kun Lee ${ }^{1}$, Hong Guan², and Yew-Chaye Loo ${ }^{3}$
}

\begin{abstract}
A simple numerical modelling technique is proposed for estimating the shear-lag behaviour of framed-tube systems with multiple internal tubes. The system is analysed using an orthotropic box beam analogy approach in which each tube is individually modelled by a box beam that accounts for the flexural and shear deformations, as well as the shear-lag effects. The method idealises the tube(s)-in-tube structure as a system of equivalent multiple tubes, each composed of four equivalent orthotropic plate capable of carrying loads and shear forces. The numerical analysis so developed is based on the minimum potential energy principle in conjunction with the variational approach. The shear-lag phenomenon of such structures is studied taking into account the additional bending stresses in the tubes. Structural parameters governing the shear-lag behaviour in tube(s)-in-tube structures are also investigated through a series of numerical examples.
\end{abstract}

Key words: highrise building, framed-tube structures, shear-lag, orthotropic box beam, tubetube interaction

\section{INTRODUCTION}

Modern highrise buildings of the framed-tube system exhibit a considerable degree of shear-lag with consequential reduction in structural efficiency. Despite this drawback, framed-tube structures are widely accepted as an economical system for highrise buildings. This is because in the framed-tube system the lateral load resisting elements are placed on the outer perimeter. Such building systems are usually equipped with service cores, or internal tubes that are often designed to provide added lateral stiffness to the building. The internal tubes also interact with each other as well as with the external tube. Framed-tube structures with multiple internal tubes, or tubes-in-tube

\footnotetext{
${ }^{1}$ Lecturer and Research Assistant Professor, Advanced Structure Research Station, Hanyang University, Haengdang-dong 17, Sungdong-Ku, Seoul 133-791, Korea

2 Lecturer, School of Engineering, Griffith University Gold Coast Campus, PMB 50 Gold Coast Mail Centre, Queensland 9726, Australia

${ }^{3}$ Professor and Head, School of Engineering, Griffith University Gold Coast Campus, Australia
} 
structures, are widely used due to their high stiffness in resisting lateral loads and the availability of the internal tubes in supporting vertical loads.

A typical framed-tube structure under lateral loading is shown in Fig. 1. The structure behaves differently from that predicted by the primary bending theory, in that the stress distribution in the flange wall panels is not uniform, and that in the web wall panels is nonlinear. These are illustrated in Fig. 2. This nonlinear phenomenon is referred to as "shear-lag". Positive shear-lag refers to the case where the stresses in the corner columns of the flange frame panels exceed those in the centre columns. This leads to the warping of the floor slabs which, in turn, causes the deformation of the interior partitions and other secondary components. In the case of negative shear-lag, where the stresses in the centre columns exceed those in the corner columns, local buckling on the compression side and cracking on the tension side of the flange frame may occur. In addition, the tube-tube interactive stresses, referred to as the additional bending stresses, would further complicate the shear-lag prediction.

The occurrence of shear-lag has long been recognised in hollow box girders as well as in tubular structures. Foutch and Chang (1982) and Chang and Zheng (1987) observed the negative shear-lag phenomenon in box girders. Since then negative shear-lag effects have been considered in box girder design. However little effort has been made to understand the cause and the characteristics of such phenomenon. Recently, Kristek and Bauer (1993) and Singh and Nagpal (1995) also observed the existence of negative shear-lag in framed-tube structures. Yet, there is no comprehensive study on the net shear-lag behaviour or on the tube-tube interaction.

It has been noted that existing models for approximate analysis not only ignore the contribution of the internal tubes to the overall lateral stiffness but also neglect the negative shearlag effects in the tubes. Thus, these models can cater only for the structural analysis of the external tube but fail to consider the shear-lag phenomenon of the internal tubes. As a result, they are inadequate in capturing the true behaviour of such structures. Note also that the tube-tube interaction coupled with the negative shear-lag in the tubes further complicates the estimation of the structural performance and the accurate analysis of framed-tube structures.

The additional bending stresses due to the tube-tube interaction are considered capable of revealing the shear-lag phenomenon in tube(s)-in-tube structures. However, existing simple analytical methods and existing commercial 3-D frame analysis programs do not take into account 
the additional bending stresses and hence, they cannot be used to interpret the cause of the shearlag phenomenon existing in the tubes. In view of this, a simplified method needs to be developed to determine the additional bending stresses and the axial stress distributions in columns as well as to study the shear-lag reversal points.

A simple numerical modelling technique is thus proposed for estimating the shear-lag effects of tube(s)-in-tube structures. Such building system is analysed using an orthotropic box beam analogy approach in which each tube is individually modelled by a box beam that accounts for the flexural and shear deformations, as well as the shear-lag effects. The method idealises the tube(s)in-tube structure as a system of equivalent multiple tubes, each composed of four equivalent orthotropic plate panels capable of carrying axial loads and shear forces. Using simplified assumptions in relation to the patterns of strain distributions in external and internal tubes, the structural behaviour is reduced to the mere solution of a single second order linear differential equation. The numerical analysis so developed is based on the minimum potential energy principle in conjunction with the variational approach.

Three 40-storey framed-tube structures with single, two and three internal tubes are analysed using the proposed method. These structures are also analysed using a 3-D frame analysis program (ETABS, 1989). The results are compared to demonstrate the simplicity and accuracy of the proposed method. The numerical results indicating the additional bending stresses and shear-lag reversal points can then be used to estimate the shear-lag behaviour and its effect on such structures.

Four nondimensional structural parameters governing the shear-lag behaviour are also discussed. These parameters are:

(1) Stiffness factor $S_{f}$, i.e., the ratio of the shear rigidity and the column bending stiffness;

(2) Stiffness ratio $S_{r}$, i.e., the ratio of the bending stiffness of the column and that of the beam;

(3) Ratio $g$, number of storeys on number of bays in direction of the flange frame;

(4) Number of internal tubes $N$.

Consequently, the shear-lag characteristics of framed-tube structures with and without internal tubes can be identified. 


\section{SHEAR-LAG IN TUBE(S)-IN-TUBE STRUCTURES}

\section{$2.1 \quad$ Structural modelling}

A discrete framed-tube structure with multiple internal tubes (2 in this case) is shown in Fig. 3. The structure is modelled using equivalent multiple tubes, each composed of four equivalent orthotropic plate panels of uniform thickness. Consequently, a framed-tube structure may be analysed as a continuum (Lee, et al. 1998). The floor slabs in the structure are also considered to be rigid diaphragms within their own plane. Thus, the high in-plane stiffness of the slabs restricts the relative lateral displacements between the multiple tubes at each level.

It is assumed that the structure has two horizontal axes of symmetry ( $x$ and $y$ ) with the vertical axis (z) passing through the centre of its cross section. Based on this assumption, the strain distributions in the external web frame panels are identical, whereas those in the external flange frame panels are equal but opposite (see Fig. 4). A similar assumption for the strain distributions in the external tube is also applied to the internal tubes (Lee, et al. 1998).

\subsection{Vertical displacements in flange and web frame panels}

The shape functions adopted herein are the modified Reissner's functions (Reissner, 1945; Lee, et al., 1998). Essentially, the modification involves up-grading the displacement functions from the parabolic variation to a cubic one. This is to account for the independent distribution of vertical displacement in the flange frame panels, thereby taking into consideration the net shear-lag. The function for estimating the distribution of vertical displacement in the web frame panel is also assumed to be cubic. A pilot study (Lee and Loo, 1997) of the modified Reissner's functions indicates that they are adequate to cover the important characteristics of the shear-lag phenomenon in assessing the global behaviour of tube(s)-in-tube structures as well as the tube-tube interactions.

Shown in Figs. 5 and 6, respectively, are the general shapes for the displacement distributions in the flange and web frame panels. The general expressions are assumed as, for flange frame panel

$$
U_{1}(z, y)=c\left[\frac{d w}{d z}+\left(1-\left(\frac{y}{b}\right)^{3}\right) u_{1}(z)\right]
$$


and, for web frame panel

$$
U_{2}(z, x)=\left[\frac{d w}{d z} x+\left(\frac{x}{c}-\left(\frac{x}{c}\right)^{3}\right) u_{2}(z)\right]
$$

where $u_{1}(z)$ and $u_{2}(z)$ are the displacement functions including shear-lag coefficients due to the shear deformation; $w$ is the deflection of the structure; $b$ and $c$ are the half-widths of the flange and web frame panels of the external tube, respectively; $x, y$ and $z$ are the coordinates of the three rectangular axes (see Figs. 3 and 4).

\subsection{Solution method}

The total potential energy, $V$, of a framed-tube structure with multiple internal tubes is obtained by summing up the potential energy of the applied load and the total strain energy of the external and internal tubes. Or,

$$
\begin{aligned}
V= & t \int_{0}^{H}\left\{\int_{-c}^{c}\left(E \varepsilon_{z w}^{2}+G \gamma_{x z}^{2}\right) d x+\int_{-b}^{b}\left(E \varepsilon_{z f}^{2}+G \gamma_{y z}^{2}\right) d y\right\} d z+2 A_{c} \int_{0}^{H} E \varepsilon_{c}^{2} d z+ \\
& \int_{0}^{H}\left\{M(z) w^{\prime \prime}(z)-n(z) w(z)\right\} d z+V_{i s}(z)+\int_{0}^{H} n(z) w(z) d z
\end{aligned}
$$

where $V_{i s}$ is the total strain energy of the internal tubes; $w(z)$ is the lateral displacement of the structure; $n(z)$ is the sum of the interactive forces between the external and internal tubes; $M(z)$ is the total bending moment of the structure induced by the applied load (Lee, 1999).

Using simplified assumptions in relation to the patterns of the displacement distributions in external and internal tubes, the complex total potential energy of Eq. (2) is reduced to the mere solution of a single second order linear differential equation. The numerical analysis is based on the minimum potential energy principle in conjunction with the variational approach (Ketter, et al. 1979). 
The total potential energy given in Eq. (2) may be rewritten symbolically as

$$
V=\int_{0}^{H} F\left(z, w^{\prime \prime}, u_{1}, u_{1}^{\prime}, u_{i 1}, u_{i 1}^{\prime}\right) d z
$$

where $F$ is an assumed function which leads to the following governing differential equations based on the principle of minimum potential energy.

For the external tube,

$$
\begin{aligned}
& \frac{d}{d z}\left[u_{1}^{\prime}(z) \alpha_{2}(z)+w^{\prime \prime}(z) \alpha_{1}(z)\right]-u_{1}(z) \alpha_{3}(z)=0 \\
& \frac{d}{d z}\left[E I_{e} w^{\prime \prime}(z)-u_{1}^{\prime}(z) \alpha_{1}(z)\right]=-P_{e}(z)
\end{aligned}
$$

For the internal tube,

$$
\begin{aligned}
& \frac{d}{d z}\left[u_{i 1}^{\prime}(z) \beta_{2}(z)+w^{\prime \prime}(z) \beta_{1}(z)\right]-u_{i 1}(z) \beta_{3}(z)=0 \\
& \frac{d}{d z}\left[E I_{i} w^{\prime \prime}(z)-u^{\prime}{ }_{i 1}(z) \beta_{1}(z)\right]=-P_{i}(z)
\end{aligned}
$$

where $u_{1}(z)$ and $u_{i 1}(z)$ are the undetermined functions including shear-lag coefficients of the external and internal tubes respectively; $P_{e}(z)$ and $P_{i}(z)$ are the total shear forces in the external and internal tubes, respectively, due to the lateral load; $\alpha_{1}, \alpha_{2}, \alpha_{3}, \beta_{1}, \beta_{2}$, and $\beta_{3}$ are the constants to be determined using the boundary conditions; $I_{e}, I_{i}$ and $I$ are the second moments of area of the external tube, internal tubes and the entire tube(s)-in-tube system, respectively (Lee, 1999).

Combining the two expressions in Eq. (4) and the same for Eq. (5) lead to

$$
u^{\prime \prime}{ }_{1}-u_{1} X^{2}=P_{e}(z) Y
$$

and

$$
u^{\prime \prime}{ }_{i 1}-u_{i 1} X_{1}^{2}=P_{i}(z) Y_{1}
$$


where $X, Y, X_{1}$ and $Y_{1}$ are given in Table 1 . Note in the table that $I_{N}$ and $I_{i N}$ are the second moments of area of the flange panels in the external and internal tubes, respectively.

The general solutions for the two non-homogeneous equations given in Eq. (6) are

$$
u_{1}(z)=A \sinh X z+B \cosh X z+C P_{e}(z) Y
$$

and

$$
u_{i 1}(z)=D \sinh X_{i} z+E \cosh X_{i} z+F P_{i}(z) Y_{i}
$$

where $A, B, C, D, E$ and $F$ are the constants to be determined according to the loading conditions.

\subsection{Bending stresses}

The bending stresses of tube(s)-in-tube structures can be derived from the governing differential equations. Note that the shear-lag phenomenon is due to the distributions of the additional bending stresses, the expressions of which can be derived from those for the axial bending stresses. The axial bending stress distributions including the shear-lag effect are expressed in terms of a series of linear functions of its second moment of area, $I$, of the entire tube(s)-in-tube system and its corresponding geometric and material properties as well as the applied load (Lee, et al. 1998).

For a tube(s)-in-tube structure, the bending stresses in the external tube are

$$
\sigma_{z f}=-E\left[\frac{M(z)}{E I} c-\left(1-\left(\frac{y}{b}\right)^{3}+\frac{I_{N}}{I}\right) c u_{1}^{\prime}(z)-\frac{I_{i N}}{I} c u_{i 1}^{\prime}(z)\right]=\sigma_{f}+\sigma_{f s}
$$

for the external flange frame panel, where $\sigma_{f}=E w^{\prime \prime} c$; and

$$
\sigma_{z w}=-E\left[\frac{M(z)}{E I} x+\left(\frac{15 b}{2}\left(\frac{x}{c}\right)-\frac{15 b}{2}\left(\frac{x}{c}\right)^{3}-\frac{I_{N}}{I} x\right) u_{1}^{\prime}(z)-\frac{I_{i N}}{I} x u_{i 1}^{\prime}(z)\right]=\sigma_{w}+\sigma_{w s}
$$

for the external web frame panel, where $\sigma_{w}=E w^{\prime \prime} x$. 
The bending stresses for the internal flange frame panels are derived as

$$
\sigma_{\text {zif }}=-E\left[\frac{M_{i}(z)}{E I_{i}} c_{i}-\left(1-\left(\frac{y}{b_{i}}\right)^{3}+\frac{I_{i N}}{I_{i}}\right) c_{i} u_{i 1}^{\prime}(z)\right]=E w^{\prime \prime} c_{i}+\sigma_{\text {fis }}
$$

for a structure with single internal tube;

$$
\sigma_{\text {zif }}=-E\left[\frac{M_{i}(z)}{E I_{i}} c_{i}-\left(1 \pm 8\left(\frac{y-n_{1}}{2 b_{i}}-\frac{1}{2}\right)^{3}+\frac{I_{i N}}{I_{i}}\right) c_{i} u_{i 1}^{\prime}(z)\right]=E w^{\prime \prime} c_{i}+\sigma_{\text {fis }}
$$

for a structure with an even number of internal tubes, where $n_{1}=\frac{(n-1)}{2} a+2\left(\frac{n}{2}-1\right) b_{i}$, $n=2\left(\frac{N}{2}\right) !$ and $N=2,4,6$, etc; and

$$
\sigma_{\text {zif }}=-E\left[\frac{M_{i}(z)}{E I_{i}} c_{i}-\left(1 \pm 8\left(\frac{y-n_{1}}{2 b_{i}}-\frac{1}{2}\right)^{3}+\frac{I_{i N}}{I_{i}}\right) c_{i} u_{i 1}^{\prime}(z)\right]=E w^{\prime \prime} c_{i}+\sigma_{f i s}
$$

for a structure with an odd number of internal tubes, where $n_{1}=\frac{(n-1)}{2} a+2\left(\frac{n}{2}-1\right) b_{i}$, $n=2\left(\frac{N-1}{2}\right) !+1$ and $N=3,5,7$, etc.

Finally for the internal web frame panel, the bending stress is

$$
\sigma_{z i w}=-E\left[\frac{M_{i}(z)}{E I_{i}} x+\left(\frac{15 b_{i}}{2}\left(\frac{x}{c_{i}}\right)-\frac{15 b_{i}}{2}\left(\frac{x}{c}\right)^{3}-\frac{I_{i N}}{I} x\right) u_{i 1}^{\prime}(z)\right]=E w^{\prime \prime} x+\sigma_{\text {wis }}
$$

Note in Eq. (8) that, $\sigma_{f s}$ and $\sigma_{w s}$ are, respectively, the additional bending stresses in the external flange and web frame panels; $\sigma_{\text {fis }}$ and $\sigma_{\text {wis }}$ are the corresponding stresses in the internal flange and web frame panels. These additional bending stresses are due to the shear-lag effect induced by the tube-tube interaction where 


$$
u_{1}^{\prime}(z)=\frac{q Y}{X^{2}}\left[\frac{\cosh X(H-z)+X H \sinh X z}{\cosh X H}-1\right]
$$

and

$$
u_{i 1}^{\prime}(z)=\frac{q Y_{1}}{X_{1}^{2}}\left[\frac{\cosh X_{1}(H-z)+X_{1} H \sinh X_{1} z}{\cosh X_{1} H}-1\right]
$$

Note also that $M_{i}(\mathrm{z})$ is the total bending moment of the internal tubes; $N$ is the number of internal tubes; $H$ is the total height of the building; $q$ is the uniformly distributed load per unit height; $a$ is the space between internal tubes, and $b_{i}$ and $c_{i}$ are the half-widths of the flange and web frame panels of the internal tubes, respectively (see Fig. 4).

In Eq. (8a), $\sigma_{f s}(y=b)$ is the additional bending stress in the corner columns of the external flange frame panels due to the shear-lag effect. If this stress $\sigma_{f s}(y=b)$ has the same sign as the bending stress $\sigma_{f}(y=b)$ generated by the external moment, stress $\sigma_{z f}(y=b)$ given in Eq. (8a) is then larger than that computed by the elementary bending theory. This is due to the effect of the positive shear-lag. In a reverse case, however, it is very difficult to predict whether $\sigma_{z f}(y=b)$ is larger or smaller than the computed value using the primary bending theory. This is a result of the negative shear-lag effect. The magnitude of this effect depends on the ratio of $\sigma_{f s}$ and $\sigma_{f}$. Thus the additional bending stress, $\sigma_{f s}$, plays an important role in demonstrating the effect of positive and negative shear-lag. A similar procedure can also be applied to evaluate the additional bending stress in the internal flange frame panels.

\section{NUMERICAL EXAMPLES}

To demonstrate the simplicity and accuracy of the proposed method, three reinforced concrete framed-tube structures (of 40-storey construction) with single, two and three internal tubes are analysed and the results are compared with the 3-D frame analysis program (ETABS, 1989). The additional bending stresses due to the proposed method are estimated to reveal the shear-lag phenomenon. Note that the 3-D frame analysis program does not take into account the additional bending stresses. 
The plan views of the three structures are shown in Fig. 7. Each building has a $3.0 \mathrm{~m}$ story height and $2.5 \mathrm{~m}$ centre-to-centre column spacing. The second moment of area of each internal tube is taken to be $90 \mathrm{~m}^{4}$, and Young's modulus $E$ and shear modulus $G$ are taken to be $2.06 \times 10^{10}$ $\mathrm{N} / \mathrm{m}^{2}$ and $2.0 \times 10^{9} \mathrm{~N} / \mathrm{m}^{2}$, respectively. Note for the sake of comparison that, the values of $E$ and $G$ are computed on the basis of Kwan's theory (Kwan, 1994). To consider the critical case, a uniformly distributed lateral load of $88.24 \mathrm{KN} / \mathrm{m}$ is applied along the entire height of the structure.

Column axial forces in the flange frame panels of external and internal tubes are computed, at the $1^{\text {st }}$ and $10^{\text {th }}$ levels, using the proposed method. The results are presented in Fig. 8. Compared to the 3-D frame analysis results (ETABS, 1989), the proposed method yields good correlation in column axial force distributions for all three structures.

Comparisons of the lateral deflections of the structures as well as the column axial forces in web frame panel of external tube also show the accuracy of the proposed method (Lee, 1999). It is worth mentioning that the proposed method requires minimal data preparation effort, and for each analysis, the personal computer running time is absolutely negligible when compared with the 3-D frame analysis program. In view of its simplicity, efficiency and accuracy, the proposed method is considered to be a suitable design tool for framed-tube structures, particularly at the preliminary stage where numerous analysis iterations need to be carried out.

Fig. 9 shows the distributions of the additional bending stresses in the centre and corner columns of the flange frame panels for the three structures. It is found, for the internal tubes, that as their second moments of area are identical, increasing the number of internal tubes gradually reduces the increment in the additional bending stresses from centre to corner columns. In other words, a reduction occurs in the bending stresses between centre and corner columns. As a result, the shear-lag is also reduced. However, the number of internal tubes does not have much effect on the additional bending stresses in the external tubes. It is further observed, in the external tubes, that the effect of the positive shear-lag is greater at the bottom of the structures, whereas the negative shear-lag occurs at around 1/4 of the building height. For all three structures, the shearlag reversal point for the internal tubes locates at the bottom of the structures. 


\section{STRUCTURAL PARAMETERS GOVERNING THE SHEAR-LAG}

Due to the increase in the natural flexibility of the spandrel beams, which tie the closely spaced columns at each floor level, the positive and negative shear-lag phenomenon is more prominent in tube(s)-in-tube structures than in any other system. In addition, the shear-lag phenomenon and the tube-tube interaction in such structures further complicate the evaluation of the structural behaviour.

The shear-lag phenomenon is further investigated through four structural parameters. Numerical examples considered herein are a series of 40-storey buildings having identical plan dimensions, material properties (i.e. $E$ and $G$ ) and loading condition as those adopted in the preceding section.

The four nondimensional structural parameters governing the shear-lag behaviour are:

(1) Stiffness factor $S_{f}$ representing the ratio of the shear rigidity and the column bending stiffness, or

$$
S_{f}=\frac{12 h}{A_{c} d^{2}} \frac{1}{\left(\frac{h}{I_{c}}+\frac{d}{I_{b}}\right)}
$$

where $I_{c}$ and $I_{b}$ are, respectively, the second moments of area of the column and the beam; $A_{c}$ is the sectional area of the column; $h$ is the storey height; $d$ is the bay width or span.

(2) Stiffness ratio $S_{r}$, the ratio of the bending stiffness of the column and that of the beam, or

$$
S_{r}=\frac{I_{c} d}{I_{b} h}
$$

(3) Ratio $g$, i.e. the number of storeys on the number of bays in the external flange frame panel;

(4) Number of internal tubes, $N$. 
Table 2 shows the four parameters $S_{f}, S_{r}, g$ and $N$ calculated for the tube(s)-in-tube structures. In total, thirty-three such structures with different numbers of internal tubes are analysed. They are classified as the $F, R, S T, D T$ and $C T$ groups. The grey areas in the table indicate the varying structural parameters for each group. Note that the $F$ group contains structures of different $S_{f}$ (by modifying the value of $A_{c}$ ), while keeping $I_{c}, I_{b}, S_{r}, g$ and $N$ constant. The $R$ group contains structures of different $S_{r}$ (by changing the values of $I_{c}$ and $I_{b}$ ), while keeping $S_{f}, g$ and $N$ constant. Similarly, the $S T$ and $D T(C T)$ groups contain structures of different $g$ and $N$, respectively, while keeping the other parameters constant. Note also that the difference between the $D T$ and $C T$ groups is that the second moments of area of internal tubes are varying in $D T$ group but constant in CT group.

To investigate the shear-lag phenomenon in the front columns of the external flange frame panel, the ratio $p$ is introduced as the ratio of the axial force in the corner column and that in the centre column. A value of $p$ greater than unity suggests a positive shear-lag. Otherwise, a negative shear-lag is indicated. The storey level at which $p$ is equal to unity represents the level of shear-lag reversal.

Fig. 10 shows the variation of $p$ along $z / H$ in the external flange frame panel for different values of $S_{f}$ (i.e., 0.026, 0.04 and 0.08) while keeping $I_{c}, I_{b}, S_{r}, g$ and $N$ constant. It is found that when $S_{f}$ increases, the shear rigidity of a bay increases and hence resulting in a relatively more uniform distribution of the column axial forces, i.e., the positive and negative shear-lags are reduced.

Shown in Fig. 11 is the variation of $p$ along $z / H$ for different values of $S_{r}$ (i.e., $0.415,0.833$ and 1.673) while keeping $S_{f}, g$ and $N$ constant. An increase in stiffness ratio $S_{r}$ implies an increase in the column restraints to the rotation of the beams, hence resulting in an increased shear rigidity of a bay, i.e., the shear-lag is reduced. Note, however, that the stiffness ratio has insignificant effect on the shear-lag phenomenon.

The variation of $p$ along $z / H$ for the three values of $g$ (i.e., 1.66, 3.33 and 5.0) is presented in Fig. 12. Note that $S_{f}, S_{r}$ and $N$ remain constant. It is observed that the shear-lag, either positive or negative, decreases with an increase in the $g$ values. This phenomenon appears to be similar for structures with single and two internal tubes, and those without. It is concluded that the larger the 
ratio $g$ (i.e., the number of storeys on the number of bays), the greater the cumulative shear stiffness of the beams. This in turn leads to a reduced shear-lag.

Fig. 13 shows the variation of $p$ along $z / H$ for various values of $N$. Comparisons are made for varying and constant second moment of area of the internal tube (i.e., $I_{i}$ ). It is observed in Fig. 13(a) that when $N$ and $I_{i}$ increase, the lateral stiffness provided by the internal tube also increases, which in turn results in a reduction in shear-lag. On the other hand, however, when $N$ increases while keeping $I_{i}$ constant, little difference is found on the shear-lag behaviour between each of the three structures (see Fig. 13(b)). This implies that the structural response depends more on the second moment of area of the internal tubes than the number of the internal tubes. In addition, it is observed that for structures with lower values of $I_{i}$, the shear-lag phenomenon is more pronounced in the negative region than in positive.

Figs. 10 to 13 also show that the shear-lag reversal takes place at a low level (i.e., at about 1/3$1 / 4$ the height of the structure) except for the structure with a low value of $g$ (i.e., $g=1.66$ ) (see Fig. 12). Furthermore, the shear-lag reversal point moves towards the top of the structure with the increasing effects of shear-lag. This phenomenon is more pronounced for structures with lower values of $S_{f}$ and $g$, as apparent in Figs. 10 and 12.

\section{CONCLUSION}

A simple numerical method is proposed for the approximate analysis of framed-tube structures with multiple internal tubes. The proposed method takes into account the additional bending stresses due to the tube-tube interaction in the tubes, which are observed to have significant effect on the shear-lag phenomenon. By quantifying the additional bending stresses and the shear-lag reversal points, a better understanding of the shear-lag phenomenon of tube(s)-in-tube structures is provided.

The accuracy, simplicity and efficiency of the proposed method are verified through the comparisons with a 3-D frame analysis program. The comparative study is carried out based on the analysis of various types of tube(s)-in-tube structures. The accuracy and economy of the proposed method is confirmed. 
Four structural parameters governing the shear-lag behaviour of tube(s)-in-tube structures are investigated through a series of 40 -storey buildings. The investigation has provided important information associated with the net shear-lag, hence capable of maximising the structural performance of framed-tube structures. The study indicates that a decrease in ratios $S_{f}, S_{r}, g$ and $I_{i}$ results in an increase in shear-lag. The shear-lag phenomenon, either positive or negative, is more pronounced for structures with lower values of $S_{f}, S_{r}, g$ and $I_{i}$. It is observed that if the positive shear-lag is higher, so is the negative shear-lag, and that the shear-lag reversal point moves towards the top of the structure with the increasing effects of shear-lag. It is also found, in the flange frame panels, that the shear-lag reversal points in the internal tubes take place at a lower level than those in the external tubes.

The proposed method is simple, accurate and economical. It is especially suitable for use at preliminary design stages where a large number of structures with different features are required to be analysed repeatedly.

\section{REFERENCES}

Chang, S. T., and Zheng, F. Z. (1987): Negative shear lag in cantilever box girder with constant depth. J. Struct. Engrg., ASCE, 113(1), 20-33.

ETABS (1989): Three Dimentional Analysis of Building System, Computers and Structures Inc., Berkerky, California, U.S.A.

Foutch, D. A., and Chang, P. C. (1982): A shear lag anomaly. J. Struct. Engrg., ASCE, 108(ST7), 1653-1657.

Kwan, A. K. H. (1994): Simple method for approximate analysis of framed tube structures. $J$. Struct. Engrg., ASCE, 120(4), 1221-1239.

Ketter, R. L., Lee, G. C., and Prawel, S. P. (1979): Structural Analysis and Design. MaGraw-Hill, Inc., New York.

Kristek, V., and Bauer, K. (1993): Stress distribution in front columns of high rise buildings. $J$. Struct. Engrg., ASCE, 119(5), 1464-1483.

Lee, K. K. (1999): Orthotropic box beam analogy for analysis of framed tube structures with multiple internal tubes. PhD Thesis, Griffith University.

Lee, K. K., and Loo, Y. C. (1997): Simplified analysis of shear lag in tube-in-tube structures. Proceedings of the $2^{\text {nd }}$ China-Australia Symposium on Computation and Mechanics, Sydney, Australia, February 12-14, 1997, 113-122. 
Lee, K. K., Loo, Y. C. and Guan, H. (1998): Simplified analysis of stress distribution in framed tube structures with multiple internal tubes. Proceedings of The Fifth International Conference on Tall Buildings, Hong Kong, China, December 9-11, 1998, 345-350.

Reissner, E. (1945): Analysis of shear lag in Box Beam by the Principle of Minimum Potential Energy. Quarterly of Applied Mathematics, Vol.4, No.3, 268-278.

Singh, Y., and Nagpal, A. K. (1994): Negative shear lag in framed-tube buildings. J. Struct. Engrg., ASCE, 120(11), 3105-3121. 


\section{NOTATION}

The following symbols are used in this paper:

$$
\begin{aligned}
& A_{c}=\text { sectional area of column } \\
& b, c=\text { half-widths of external flange and web frame panels, respectively } \\
& b_{i}, c_{i}=\text { half-widths of internal flange and web frame panels, respectively } \\
& d=\text { bay width } \\
& E, G=\text { elastic and shear moduli of equivalent tube, respectively } \\
& g=\text { number of storeys on number of bays in external flange frame } \\
& \text { panel } \\
& H, h=\text { total height of building and storey height } \\
& I_{c}, I_{b}=\text { second moments of area of column and beam, respectively } \\
& I_{e}, I_{i}, I=\text { second moments of area of external tube, internal tube and entire } \\
& \text { tube(s)-in-tube system, respectively } \\
& I_{N}, I_{i N}=\text { second moments of area of flange panel in external and internal tubes, } \\
& \text { respectively } \\
& M(\mathrm{z}), M_{i}(\mathrm{z}) \quad=\quad \text { total bending moment of entire system and bending moment of internal } \\
& \text { tube } \\
& N=\text { number of internal tubes } \\
& n(z)=\text { sum of interactive forces between external and internal tubes } \\
& P_{e}, P_{i}=\text { shear forces of external and internal tubes, respectively } \\
& q=\text { uniformly distributed load per unit height } \\
& S_{f}, S_{r}=\text { stiffness factor and stiffness ratio } \\
& U_{1}(z, y), U_{2}(z, x)=\text { displacement distributions in external flange and web frame panels, } \\
& \text { respectively } \\
& U_{i 1}(z, y), U_{i 2}(z, x)=\text { displacement distributions in internal flange and web frame panels, } \\
& \text { respectively } \\
& u_{1}(z), u_{2}(z)=\text { undetermined functions for displacement distribution in external flange } \\
& \text { and web frame panels, respectively } \\
& u_{i 1}(z), u_{i 2}(z)=\text { undetermined functions for displacement distribution in internal flange } \\
& \text { and web frame panels, respectively } \\
& u_{1}^{\prime}(z), u_{2}^{\prime}(z)=\text { undetermined strain functions for strain distribution in external flange } \\
& \text { and web frame panels, respectively } \\
& u_{i 1}^{\prime}(z), u_{i 2}^{\prime}(z)=\text { undetermined strain functions for strain distribution in internal flange }
\end{aligned}
$$




$$
\begin{aligned}
& \text { and web frame panels, respectively } \\
& V=\text { total potential energy } \\
& V_{i s}=\text { total strain energy of internal tubes } \\
& w(z)=\text { deflection } \\
& x, y, z=\text { coordinates of three rectangular axes } \\
& \varepsilon_{c}=\text { strain in corner columns of external tube } \\
& \varepsilon_{z f}, \varepsilon_{z w}=\text { strains in external flange and web frame panels, respectively } \\
& \gamma_{x z}, \gamma_{y z}=\text { shear strains in web and flange frame panels of external tube, } \\
& \text { respectively } \\
& \sigma_{f}, \sigma_{w}=\text { primary bending stresses in external flange and web frame panels, } \\
& \text { respectively } \\
& \sigma_{f s}, \sigma_{w s}=\text { additional bending stresses in external flange and web frame panels, } \\
& \text { respectively } \\
& \sigma_{\text {fis }}, \sigma_{\text {wis }} \quad \text { additional bending stresses in internal flange and web frame panels, } \\
& \text { respectively } \\
& \sigma_{z f}, \sigma_{z w}=\text { bending stresses in flange and web frame panels of external tube, } \\
& \text { respectively } \\
& \sigma_{\text {zif }}, \sigma_{\text {ziw }}=\text { bending stresses in flange and web frame panels of internal tube, } \\
& \text { respectively }
\end{aligned}
$$


Table 1. Formulas for $X, Y, X_{1}$ and $Y_{1}$

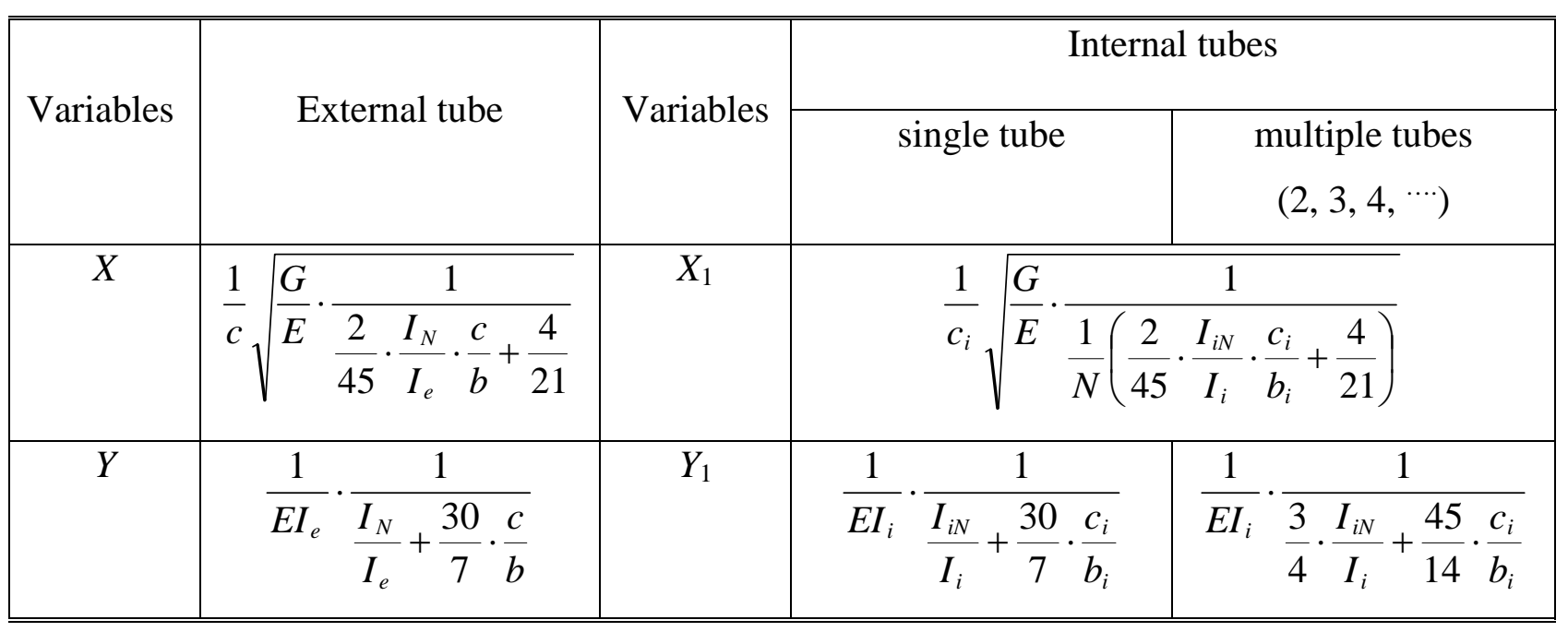


Table 2. Structural parameters $\left(S_{f}, S_{r}, g\right.$ and $\left.N\right)$ for the tube(s)-in-tube structures

\begin{tabular}{|c|c|c|c|c|}
\hline Model No. & $S_{f}$ & $S_{r}$ & $g$ & $N$ \\
\hline $1-1 F$ & 0.04 & 0.833 & 3.33 & 0 \\
\hline $1-2 F$ & 0.08 & 0.833 & 3.33 & 0 \\
\hline $1-3 F$ & 0.026 & 0.833 & 3.33 & 0 \\
\hline $2-1 F$ & 0.04 & 0.833 & 3.33 & 1 \\
\hline $2-2 F$ & 0.08 & 0.833 & 3.33 & 1 \\
\hline $2-3 F$ & 0.026 & 0.833 & 3.33 & 1 \\
\hline $3-1 F$ & 0.04 & 0.833 & 3.33 & 2 \\
\hline $3-2 F$ & 0.08 & 0.833 & 3.33 & 2 \\
\hline $3-3 F$ & 0.026 & 0.833 & 3.33 & 2 \\
\hline $1-1 R$ & 0.026 & 0.833 & 3.33 & 0 \\
\hline $1-2 R$ & 0.026 & 1.673 & 3.33 & 0 \\
\hline $1-3 R$ & 0.026 & 0.415 & 3.33 & 0 \\
\hline $2-1 R$ & 0.026 & 0.833 & 3.33 & 1 \\
\hline $2-2 R$ & 0.026 & 1.673 & 3.33 & 1 \\
\hline $2-3 R$ & 0.026 & 0.415 & 3.33 & 1 \\
\hline $3-1 R$ & 0.026 & 0.833 & 3.33 & 2 \\
\hline $3-2 R$ & 0.026 & 1.673 & 3.33 & 2 \\
\hline $3-3 R$ & 0.026 & 0.415 & 3.33 & 2 \\
\hline $1-S T 40$ & 0.04 & 0.833 & 3.33 & 0 \\
\hline 1-ST60 & 0.04 & 0.833 & 5 & 0 \\
\hline $1-S T 20$ & 0.04 & 0.833 & 1.66 & 0 \\
\hline 2-ST40 & 0.04 & 0.833 & 3.33 & 1 \\
\hline $2-S T 60$ & 0.04 & 0.833 & 5 & 1 \\
\hline $2-S T 20$ & 0.04 & 0.833 & 1.66 & 1 \\
\hline 3-ST40 & 0.04 & 0.833 & 3.33 & 2 \\
\hline 3-ST60 & 0.04 & 0.833 & 5 & 2 \\
\hline $3-S T 20$ & 0.04 & 0.833 & 1.66 & 2 \\
\hline $1-D T$ & 0.04 & 0.833 & 3.33 & 0 \\
\hline $2-D T$ & 0.04 & 0.833 & 3.33 & 1 \\
\hline
\end{tabular}




\begin{tabular}{|l|l|l|l|l|}
\hline $3-D T$ & 0.04 & 0.833 & 3.33 & 2 \\
\hline $1-C T$ & 0.04 & 0.833 & 3.33 & 1 \\
\hline $2-C T$ & 0.04 & 0.833 & 3.33 & 2 \\
\hline $3-C T$ & 0.04 & 0.833 & 3.33 & 3 \\
\hline
\end{tabular}




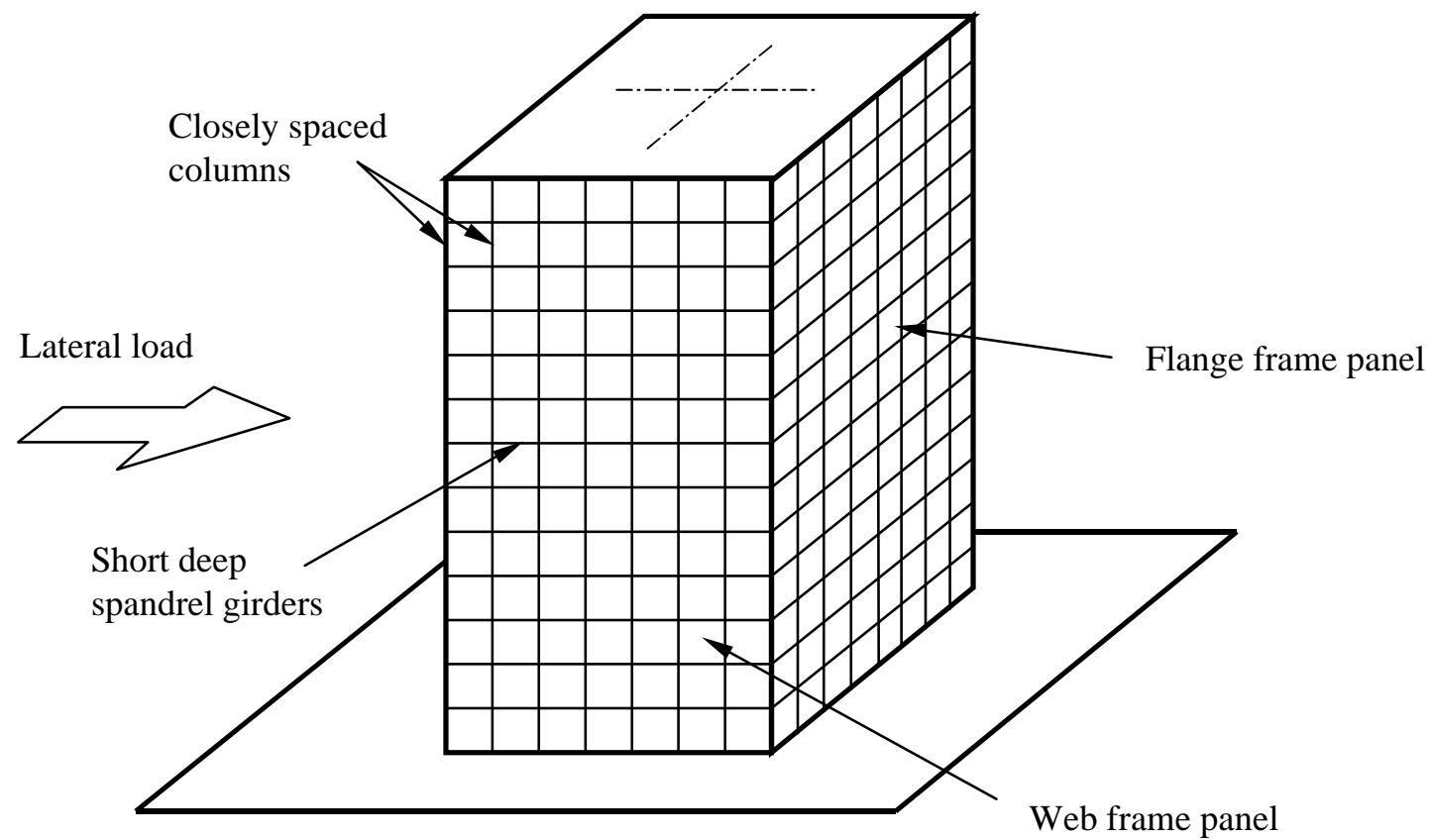

Fig. 1 Typical framed-tube structure
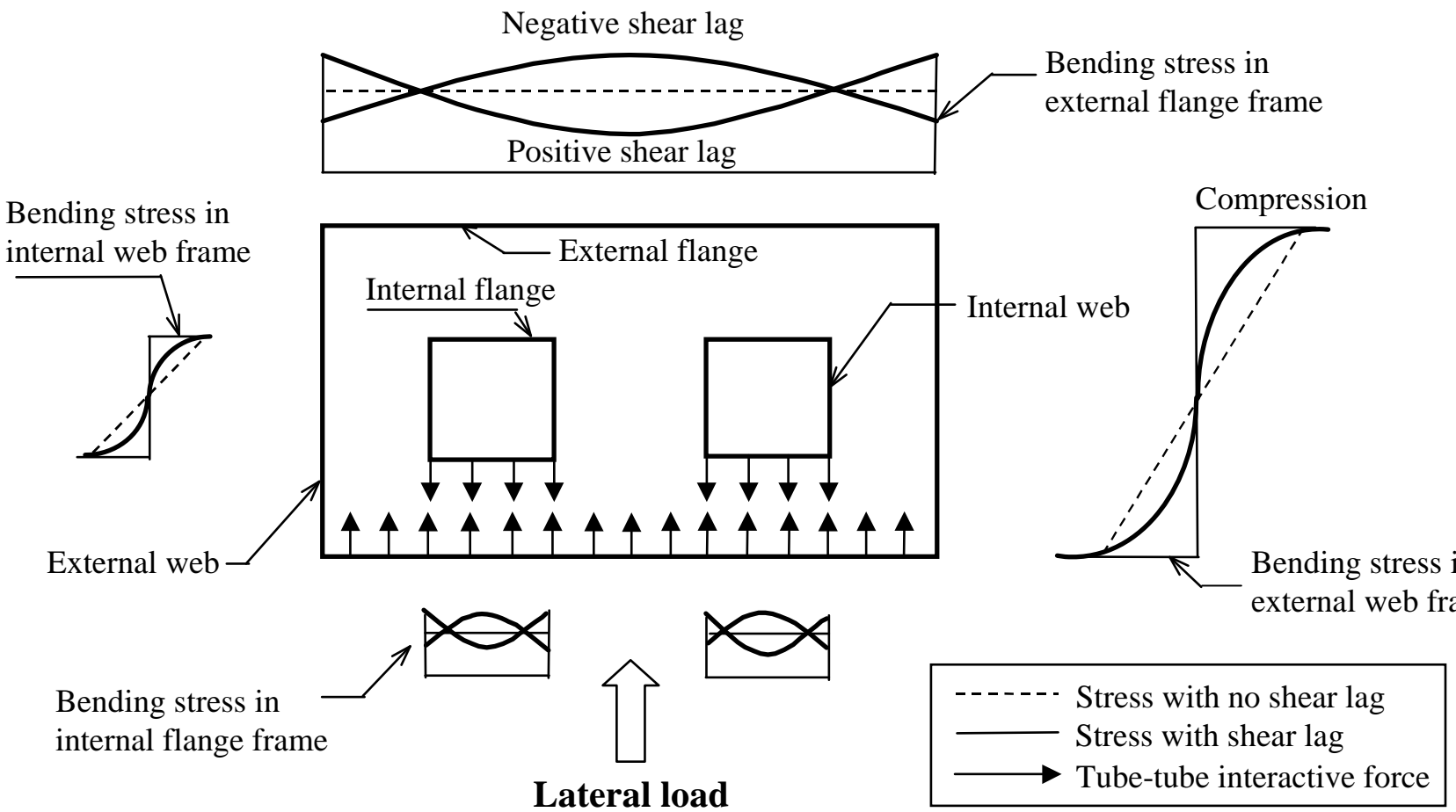

Fig. 2 Stress distribution of laterally loaded tubes-in-tube structure 


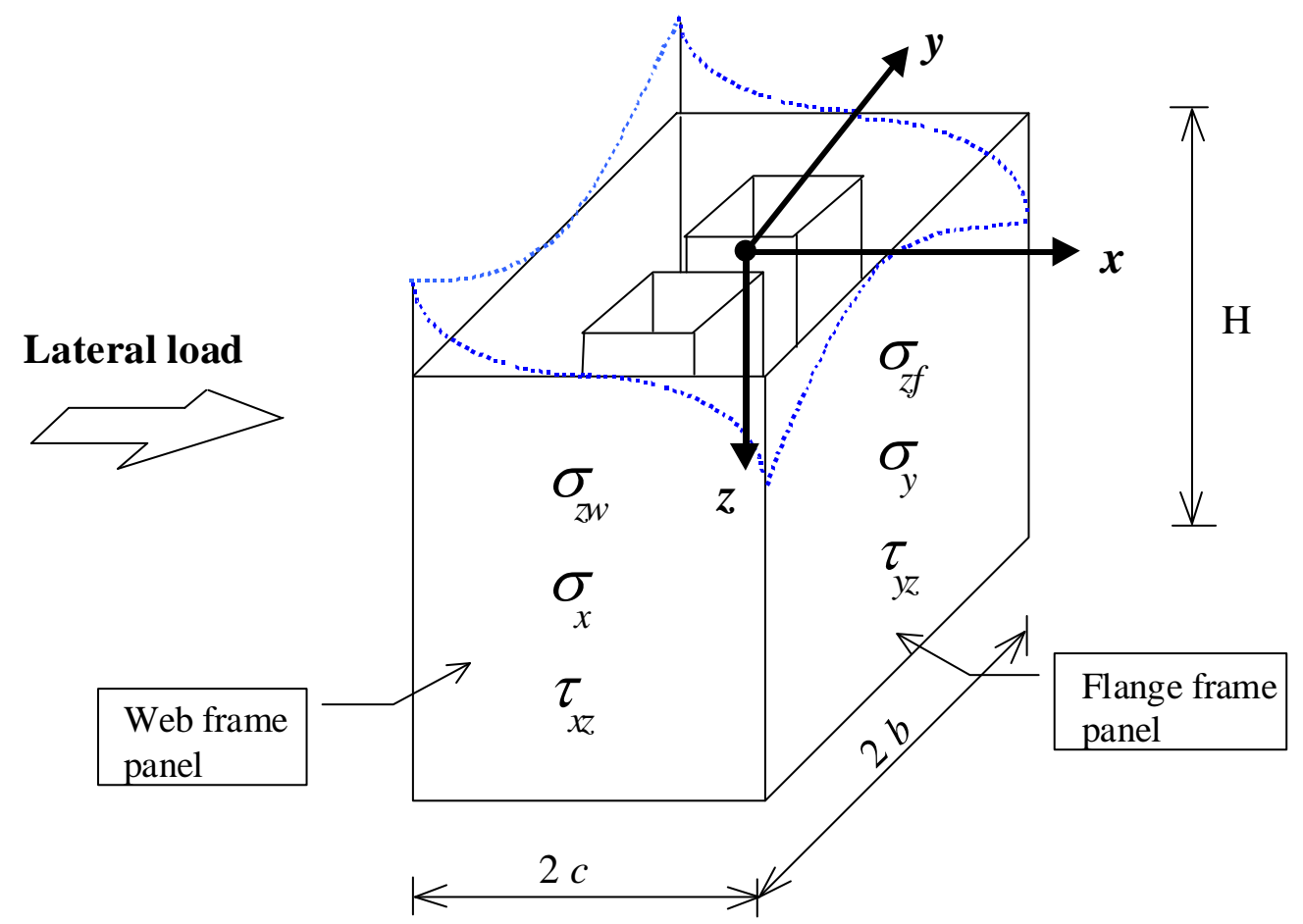

Fig. 3 Equivalent framed-tube structure with multiple (two) internal tubes

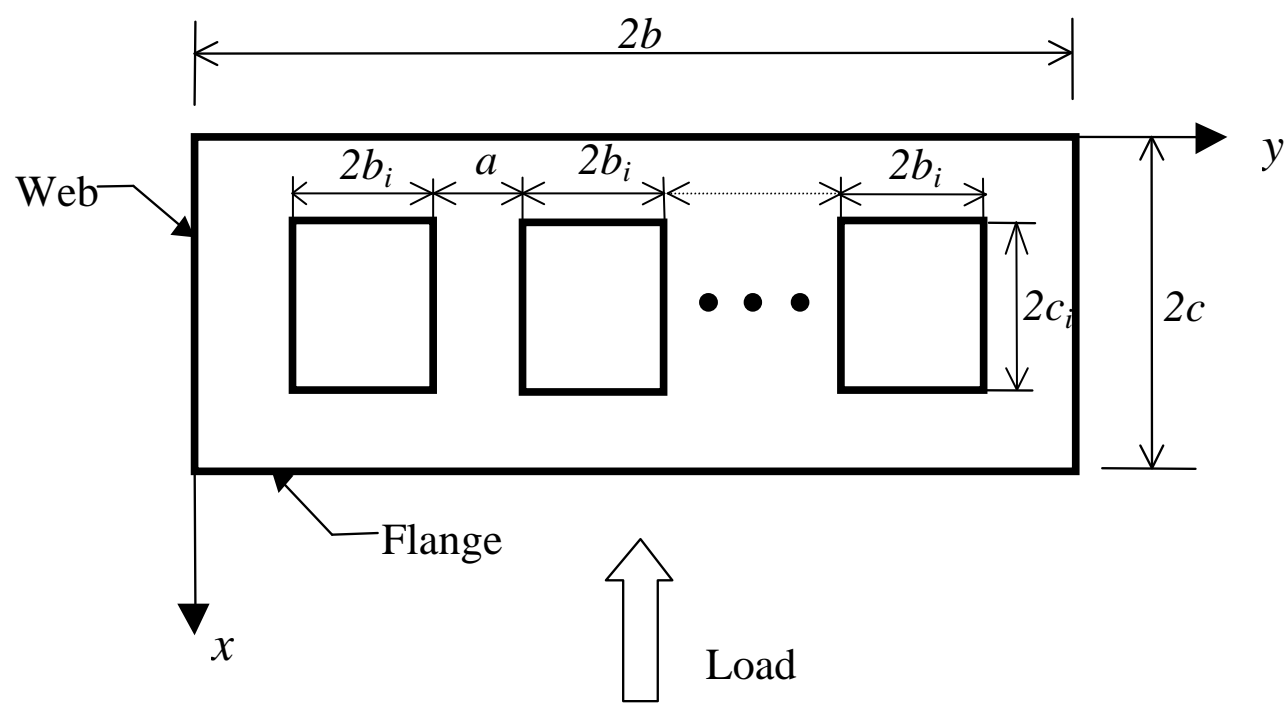

Fig. 4 Typical plan of equivalent tubes-in-tube structure 
$\frac{d w}{d z} c \underset{\downarrow}{\Downarrow}$
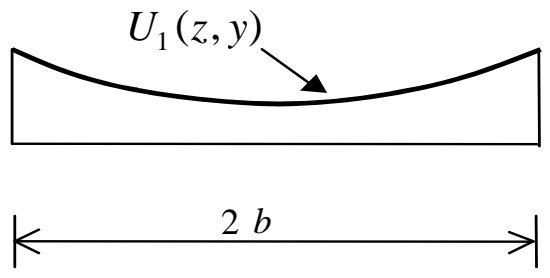

(a) Positive shear lag
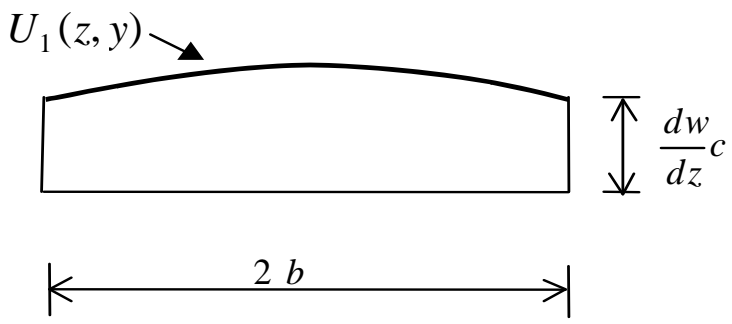

(b) Negative shear lag

Fig. 5 Distribution of vertical displacement in flange frame panel

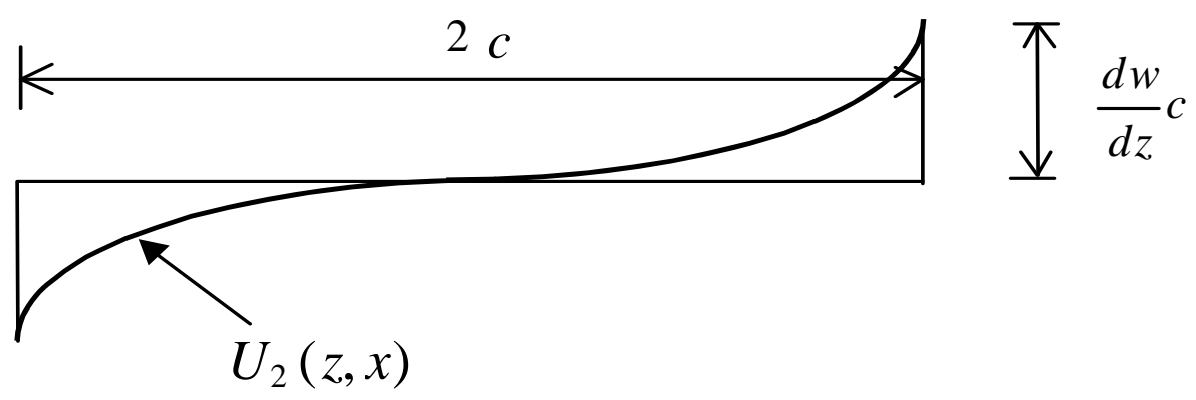

Fig. 6 Distribution of vertical displacement in web frame panel

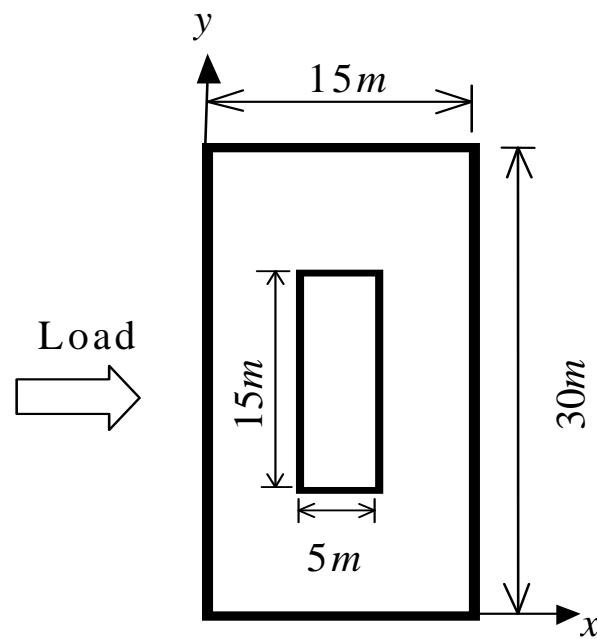

(a) Tube-in-tube

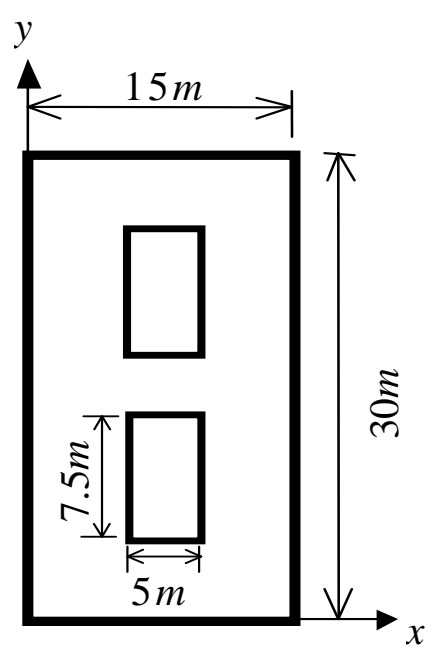

(b) Tube structure with two internal tubes

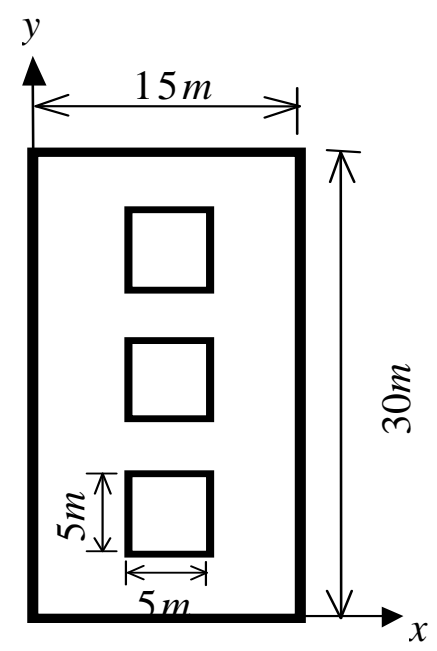

(c) Tube structure with three internal tubes

Fig. 7 Plan views of three framed-tube structures with different numbers of internal tubes 
External tube
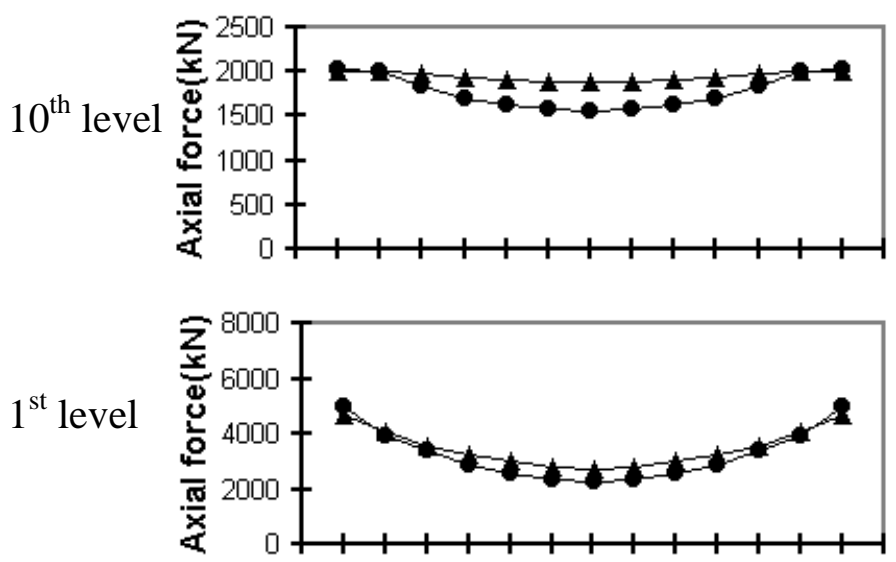

Internal tube
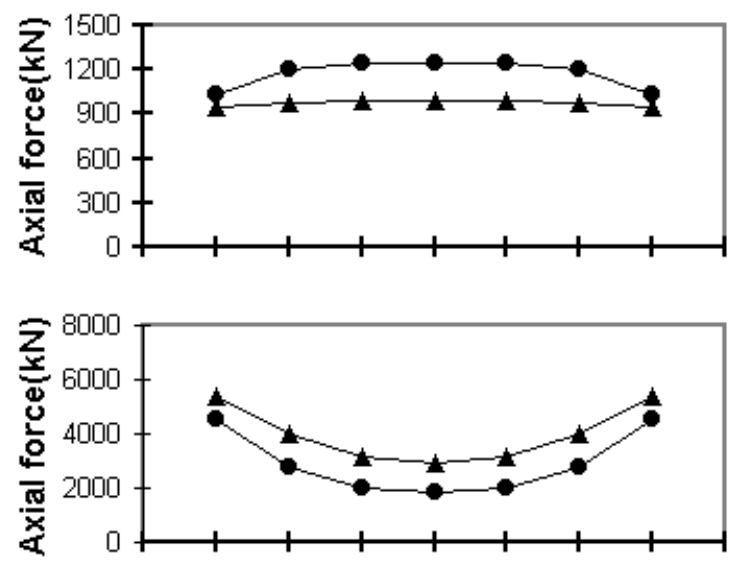

(a) Tube-in-tube structure
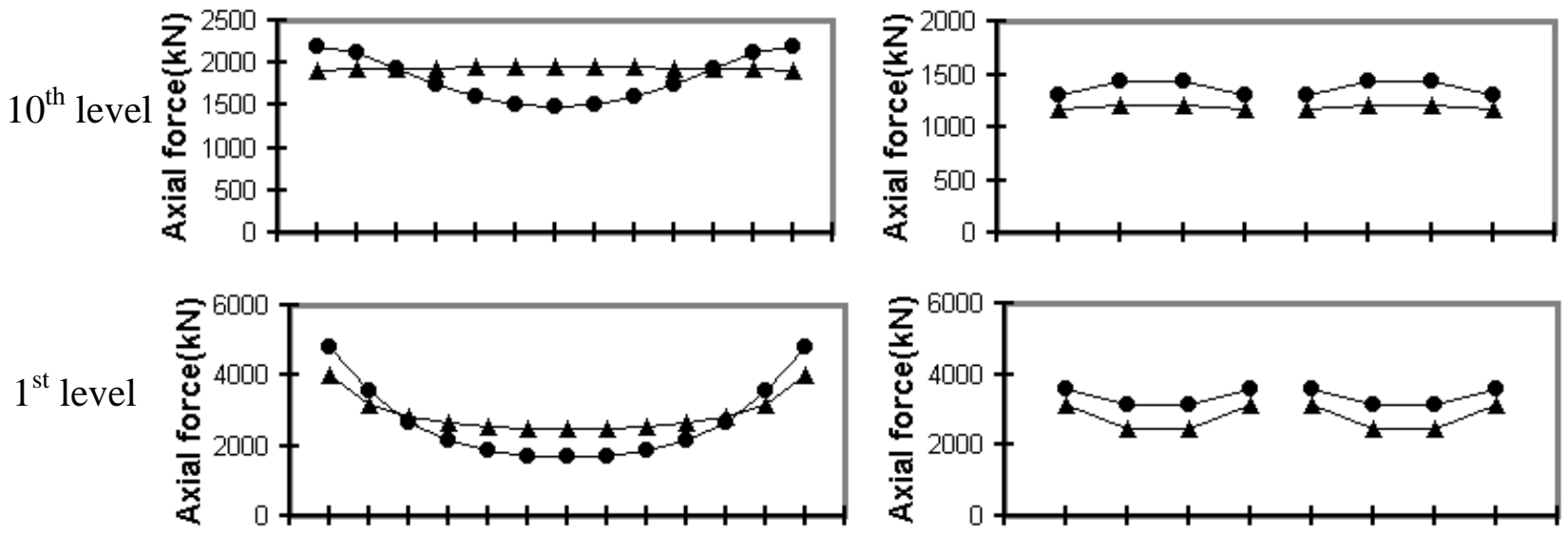

(b) 2 tubes-in-tube structure
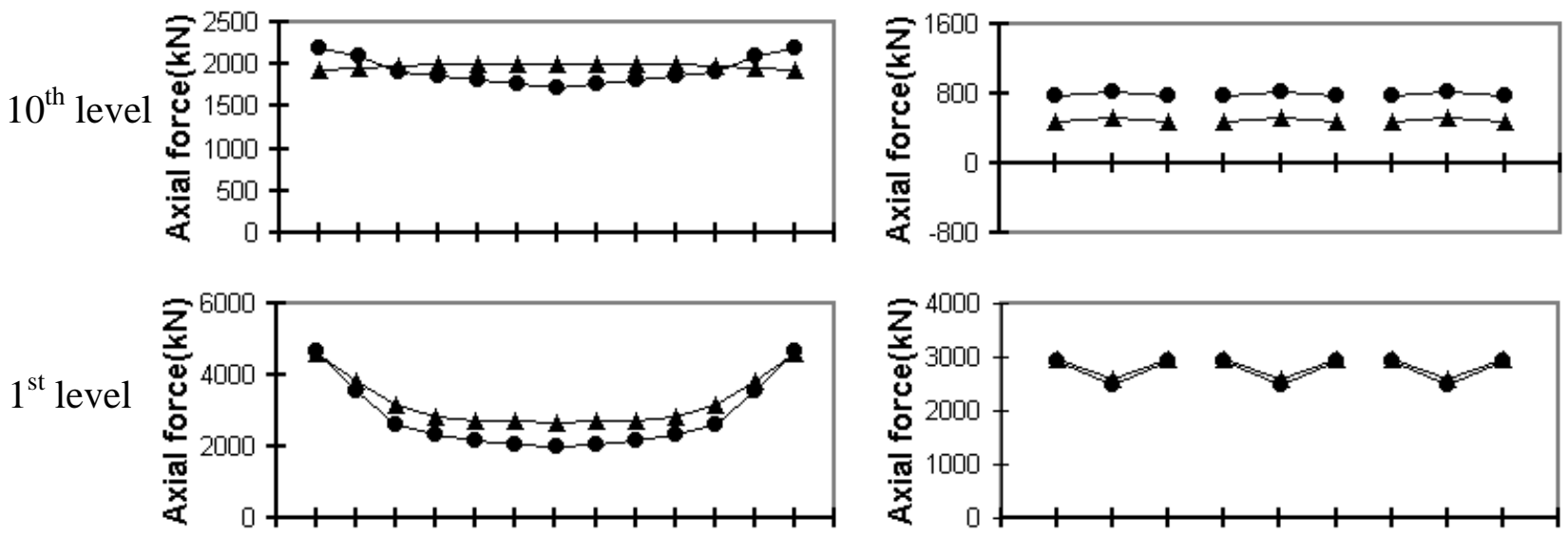

(c) 3 tubes-in-tube structure

\section{$\rightarrow-3-D$ frame analysis \\ Proposed}

Fig. 8 Column axial forces in flange frame panels of external and internal tubes (along $y$-axis) 


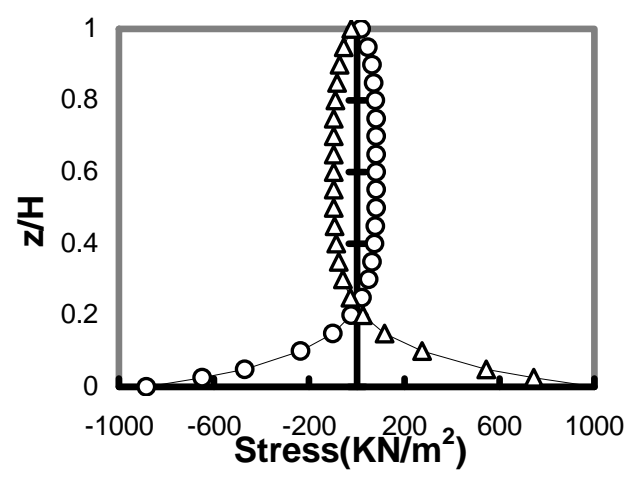

External tube

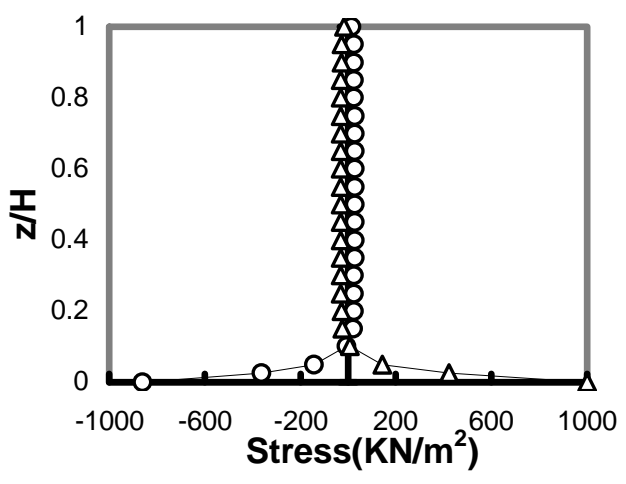

Internal tube

(a) Tube-in-tube structure

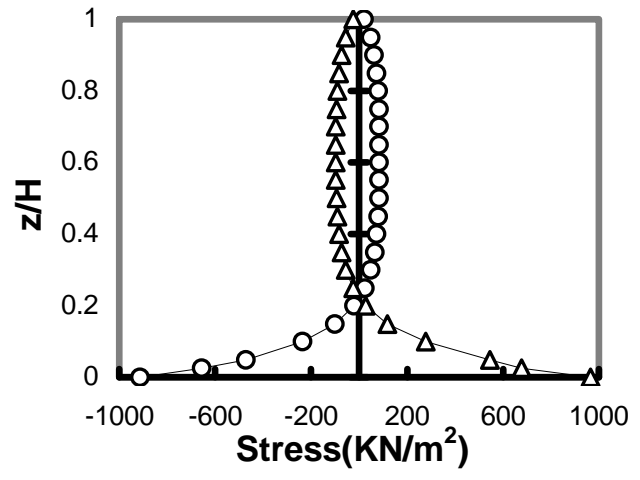

External tube

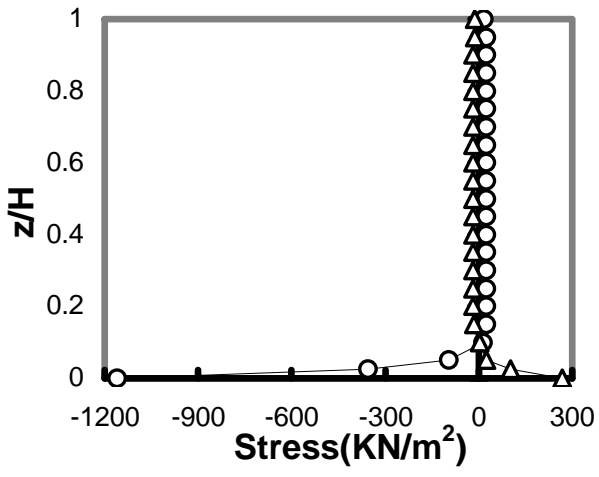

Internal tube

(b) 2 tubes-in-tube structure

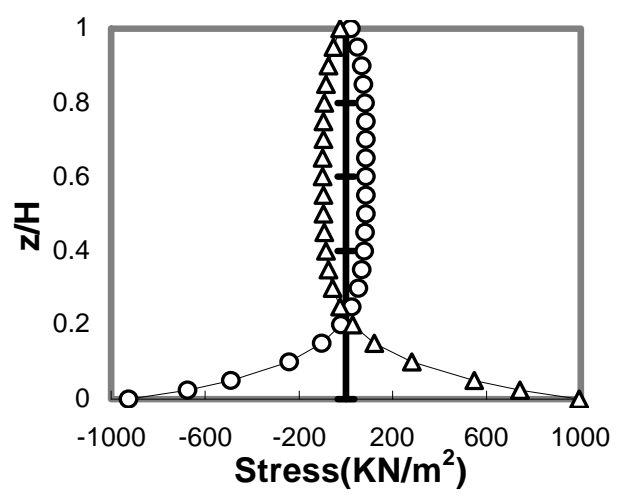

External tube

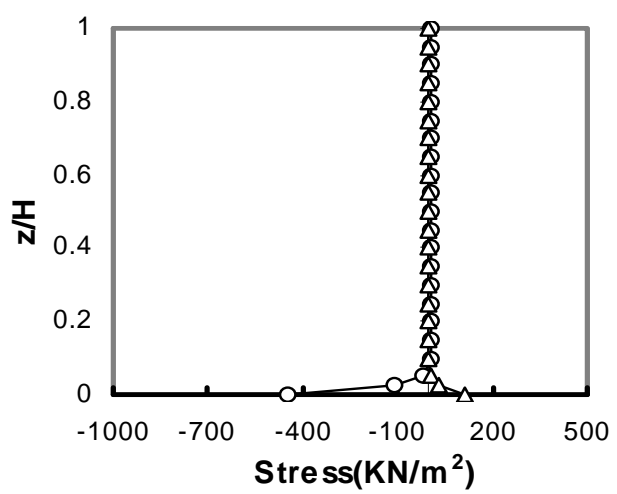

Internal tube

(c) 3 tubes-in-tube structure

$$
\begin{aligned}
& -0-\text { Centre colum n } \\
& \Delta-\text { Corner colum n }
\end{aligned}
$$

Fig. 9 Additional bending stresses in centre and corner columns of the three tube(s)-in-tube structures 


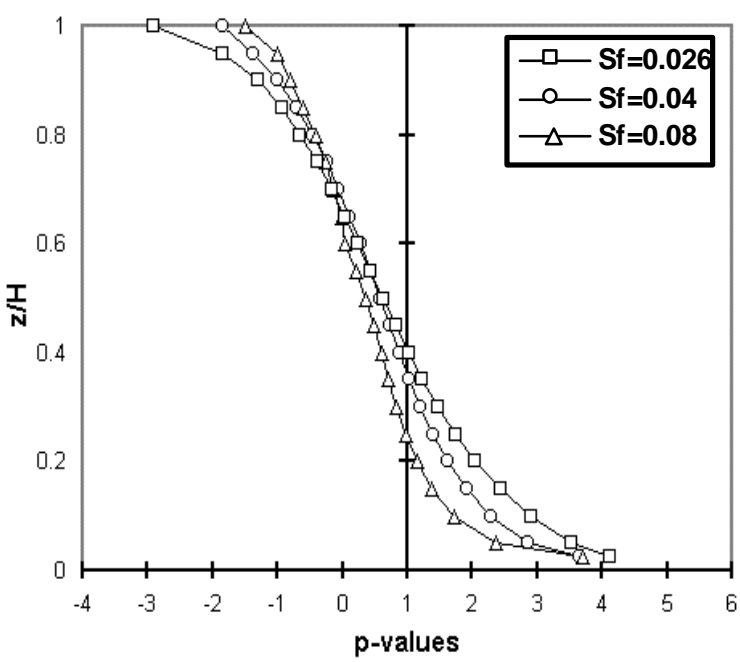

(a) Tube structure $\left(N=0, S_{r}=0.833, g=3.33\right)$

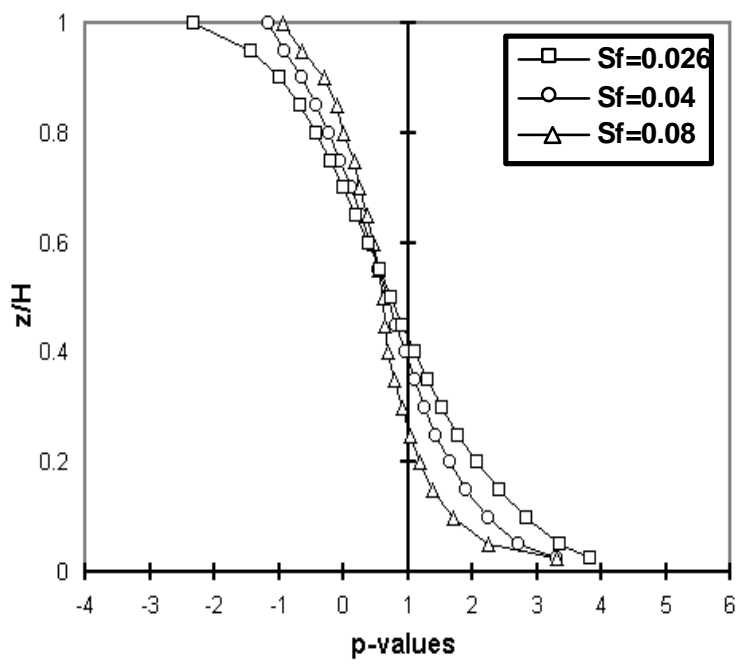

(b) Tube-in-tube structure ( $\left.N=1, S_{r}=0.833, g=3.33\right)$

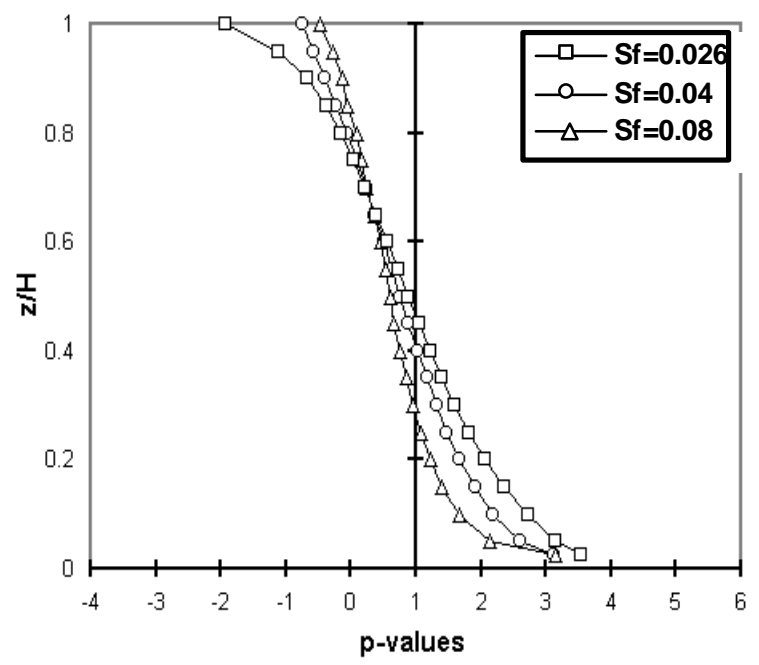

(c) 2 tubes-in-tube structure $\left(N=2, S_{r}=0.833, g=3.33\right)$

Fig. 10 Variation of $p$ for different values of $S_{f}$ 


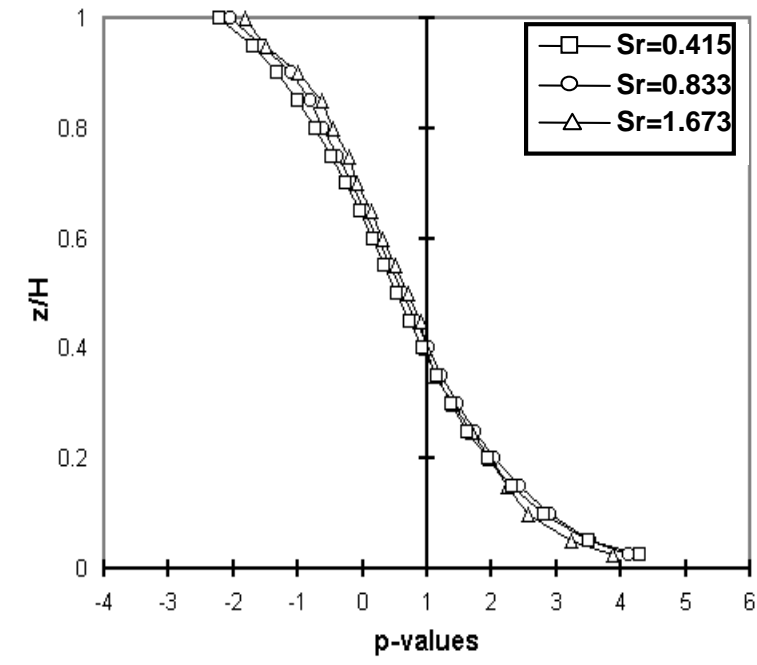

(a) Tube structure $\left(N=0, S_{f}=0.026, g=3.33\right)$

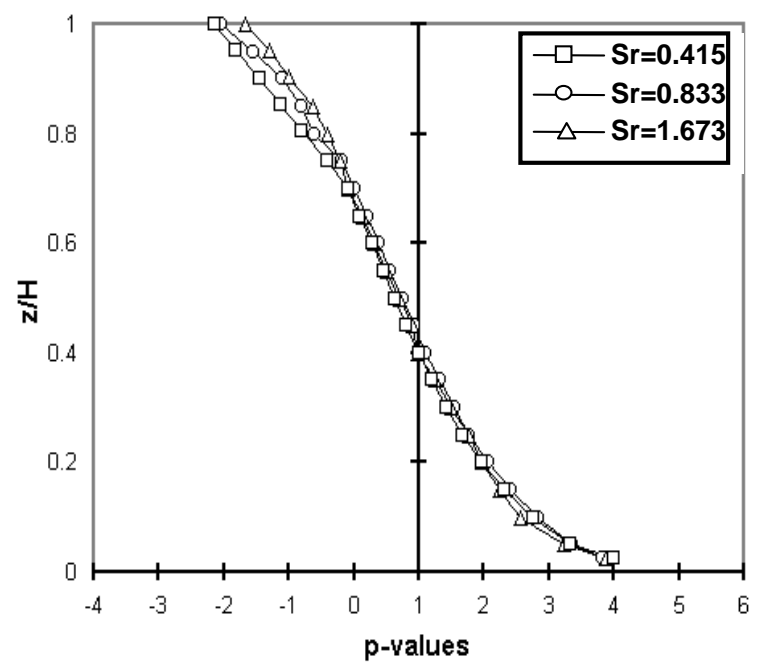

(b) Tube-in-tube structure ( $N=1, S_{f}=0.026, g=3.33$ )

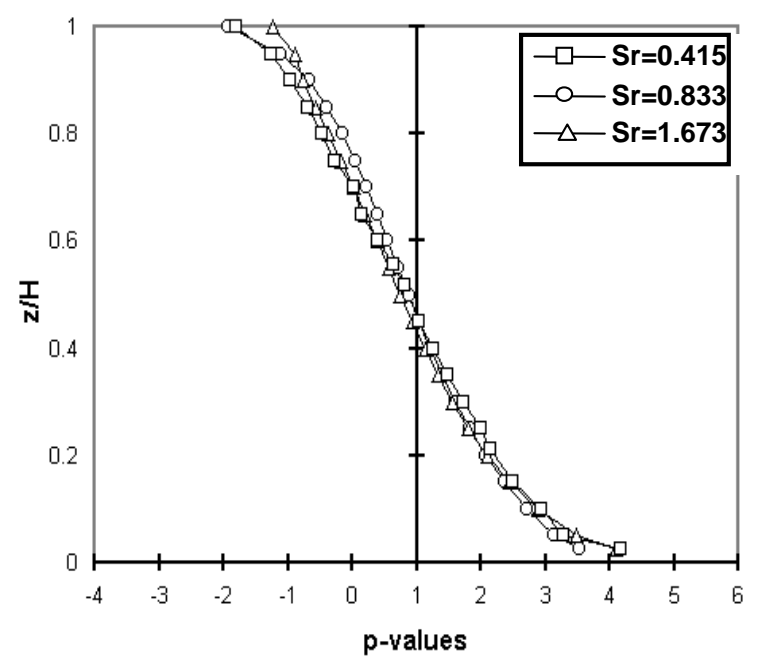

(c) 2 tubes-in-tube structure ( $N=2, S_{f}=0.026, g=3.33$ )

Fig. 11 Variation of $p$ for different values of $S_{r}$ 


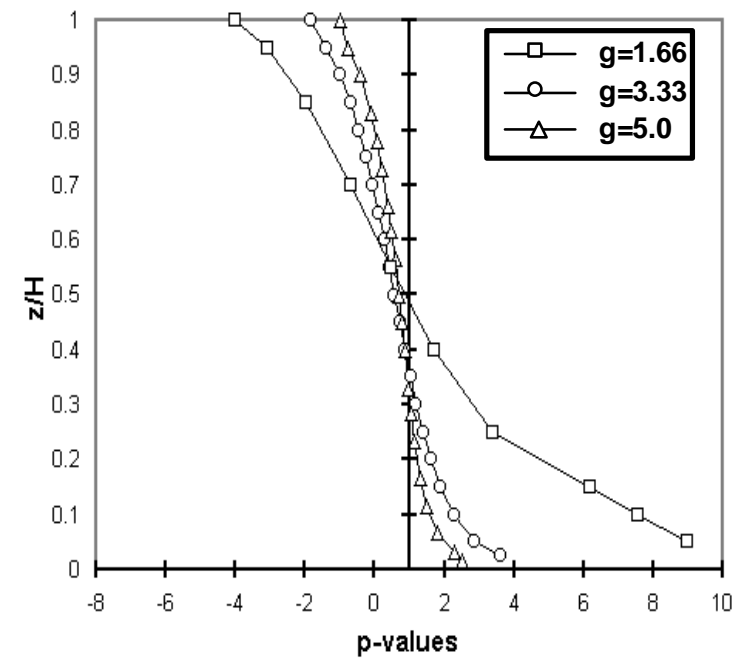

(a) Tube structure $\left(N=0, S_{f}=0.04, S_{r}=0.833\right)$

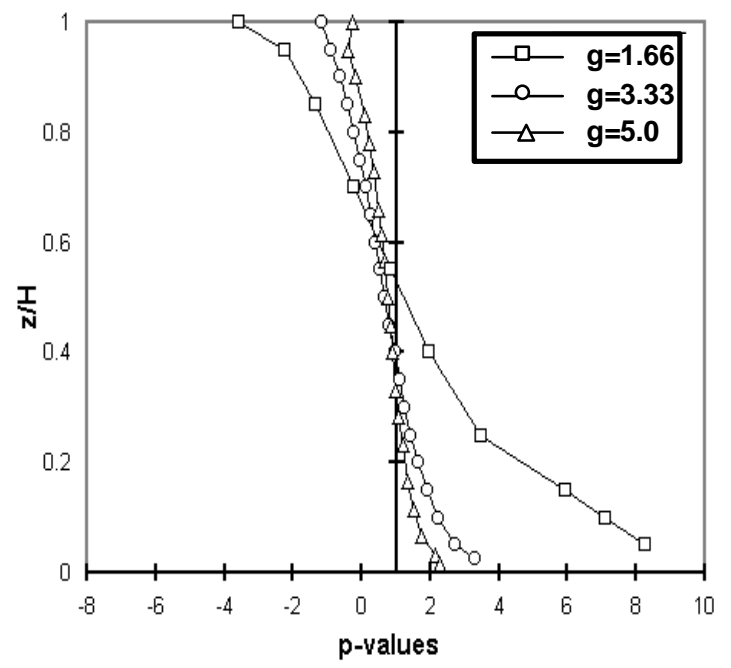

(b) Tube-in-tube structure ( $N=1, S_{f}=0.04, S_{r}=0.833$ )

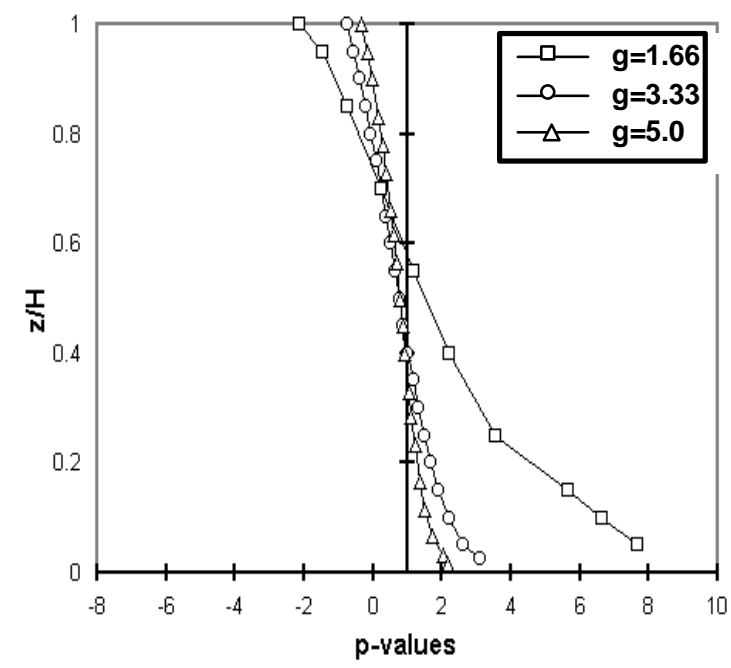

(c) 2 tubes-in-tube structure ( $N=2, S_{f}=0.04, S_{r}=0.833$ )

Fig. 12 Variation of $p$ for different values of $g$ 


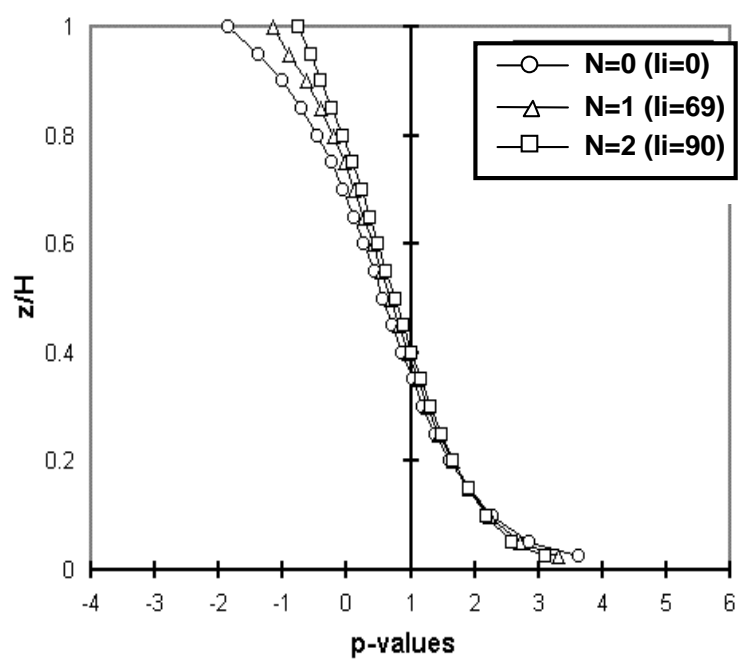

(a) For different second moment of area of internal tube $\left(I_{i}\left(m^{4}\right)\right)$

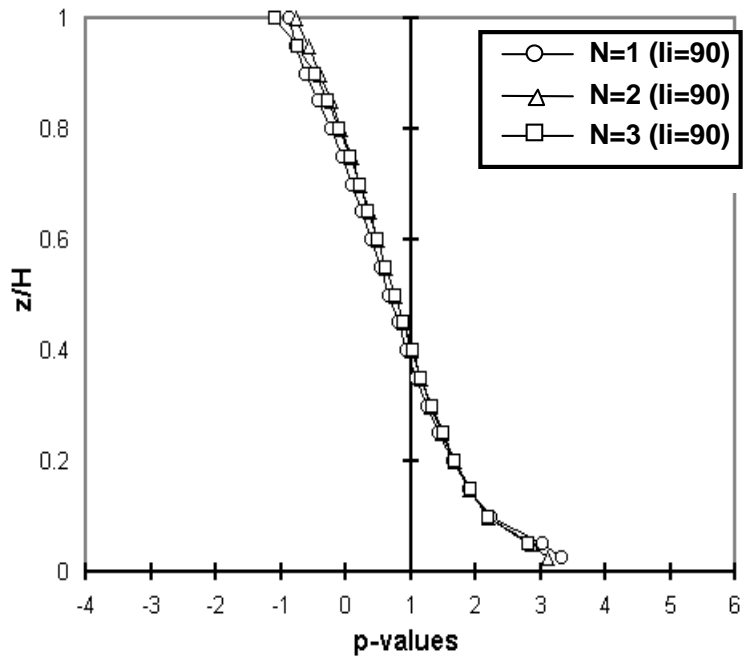

(b) For constant second moment of area of internal tube $\left(I_{i}\left(m^{4}\right)\right)$

Fig. 13 Variation of $p$ for different values of $N\left(S_{f}=0.04, S_{r}=0.833, g=3.33\right)$ 